\title{
Encapsulation of carvacrol, a monoterpene present in the essential oil of oregano, with $\beta$-cyclodextrin, improves the pharmacological response on cancer pain experimental protocols
}

\author{
Adriana Gibara Guimarães ${ }^{a}$, Marlange Almeida Oliveira ${ }^{\mathrm{b}}$, Rafael dos Santos Alves ${ }^{\mathrm{b}}$, \\ Paula dos Passos Menezes ${ }^{c}$, Mairim Russo Serafini ${ }^{c}$, Adriano Antunes de Souza Araújo ${ }^{c}$, \\ Daniel Pereira Bezerra ${ }^{\mathrm{d}}$, Lucindo José Quintans Júnior ${ }^{\mathrm{a}, *}$ \\ a Department of Health Education, Federal University of Sergipe, Lagarto, SE, Brazil \\ ${ }^{\mathrm{b}}$ Department of Physiology, Federal University of Sergipe, São Cristóvão, SE, Brazil \\ ' Department of Pharmacy, Federal University of Sergipe, Lagarto, São Cristóvão, SE, Brazil \\ d Oswaldo Cruz Foundation, Laboratory of Tissue Engineering and Immunopharmacology, Salvador, BA, Brazil
}

\section{A R T I C L E I N F O}

\section{Article history:}

Received 11 September 2014

Received in revised form 19 November 2014

Accepted 14 December 2014

Available online 31 December 2014

\section{Keywords:}

Cancer pain

Hyperalgesia

Nociception

Monoterpene

Carvacrol

$\beta$-Cyclodextrin

\begin{abstract}
A B S T R A C T
Cancer pain is a major public health problem worldwide due to the strong impact on the quality of life of patients and side effects of the existing therapeutic options. Monoterpenes, as carvacrol (CARV), have been extensively studied about their therapeutic properties, especially their importance in the control of painful conditions and inflammation, which can be improved through the use of inclusion complexes of $\beta$-cyclodextrin ( $\beta-C D)$. We evaluated the effect of encapsulation of CARV in $\beta$-CD (CARV/ $\beta-C D)$ on the nociception induced by tumor cells (Sarcoma 180) in rodents. Inclusion complexes were prepared in two different procedures and characterized through thermal analysis and scanning electron microscopy. CARV/ $\beta$-CD complex was administered $(50 \mathrm{mg} / \mathrm{kg}$, p.o.) in mice with tumor on the hind paw and was able to reduce the hyperalgesia (von Frey) during $24 \mathrm{~h}$, unlike the free CARV (100 mg/kg, p.o.), which promoted effects until $9 \mathrm{~h}$. Administration on alternate days of complex of CARV $/ \beta-C D(12.5-50 \mathrm{mg} / \mathrm{kg}$, p.o.) reduced hyperalgesia, as well as spontaneous and palpation-induced nociception. However, pure CARV $(50 \mathrm{mg} / \mathrm{kg})$ did not cause significant changes in nociceptive responses. Together, these results produced evidence that the encapsulation of carvacrol in $\beta$-cyclodextrin can be useful for the development of new options for pain management.
\end{abstract}

(c) 2014 Elsevier Ireland Ltd. All rights reserved.

\section{Introduction}

Pain is a frequent symptom in malignant neoplasms. Decades after the publication of the World Health Organization's (WHO) analgesic ladder, cancer pain is still a major cause of suffering for patients with cancer and affects millions of people worldwide. Due to the increasing incidence of cancer and the increased life

Abbreviations: $\beta$-CD, $\beta$-cyclodextrin; $C A R V / \beta-C D$, carvacrol- $\beta$-cyclodextrin complex; CARV, carvacrol; CDs, cyclodextrins; DSC, differential scanning calorimetry; PM, physical mixture; S180, Sarcoma 180; SC, slurry complex; TG/DTG, thermogravimetry/derivative thermogravimetry.

* Corresponding author at: Department of Physiology, Federal University of Sergipe, Avenue Marechal Rondom, São Cristóvão, Sergipe, Brazil. Tel.: +55 79 21056645; fax: +55 7932126640

E-mail addresses: lucindojr@gmail.com, lucindo@pq.cnpq.br (L.J. Quintans Júnior). expectancy of patients, cancer-related pain is a major public health problem worldwide [1].

At present, opioids represent one of the few therapeutic options capable of controlling moderate and severe cancer pain. However, apart from analgesia, these drugs cause many consistent side effects such as sedation, euphoria, respiratory depression, constipation, addiction and pruritus [2]. These factors can lead to poor adherence of pharmacotherapy and decreased quality of life. For this reason, there is a growing interest of research centers and the pharmaceutical industry in the discovery of new pharmacological options for the treatment or management of cancer pain.

In this context, we highlight the monoterpenes, which can be found in the essential oil of aromatic herbs. They are shown to be interesting candidates for the development of new analgesic drugs, through clinical studies in cancer patients, as reviewed by Guimarães et al. [3], and some pre-clinical reviews by Da Silveira 
e Sá et al. [4], De Sousa [5] and Guimarães et al. [6], including studies for chronic pain [7].

Carvacrol (CARV) is a phenolic monoterpene found in essential oils of the family Lamiaceae, including the genera Origanum and Thymus [8]. Several studies have demonstrated that CARV presents pharmacological effects of interest, such as analgesic, anti-inflammatory, antitumor and antioxidant [9-12]. Recently, CARV was shown to be a pharmacologically relevant agent on cancer pain control, activating brain areas involved in descending inhibitory control of pain [13], besides being able to decrease the release of inflammatory mediators [14-16]. However, employment of these compounds by the pharmaceutical industry can present disadvantages from the technological point of view, in the preparation and storage process due to their instability, easy sublimation and the low water solubility, which can all limit their application.

Cyclodextrins (CDs) are cyclic oligosaccharides that have recently been recognized as useful tools for optimizing the delivery of such problematic drugs and also for drugs having other undesirable properties such as objectionable taste and odor, and irritation potential. This excipient (FDA approved and described in pharmacopoeias of several countries) can be found in at least in 35 pharmaceutical products, as anticancer agent and anti-inflammatory drugs, predominantly as $\beta-C D$ [17]. Besides, several recent studies have demonstrated that the complexation of monoterpenes with $\beta$-CD provides benefits in solubility and stability. It could also improve pharmacological response mainly to pain control [18-21].

Based on the foregoing, it is expected that the use of carvacrol$\beta$-cyclodextrin complex (CARV/ $\beta-C D)$ can be an alternative for the treatment of pain associated with cancer. Hence, the aim of our study was to optimize the biopharmaceutical properties of CARV, through the use of inclusion complexes of $\beta$-cyclodextrin, in order to improve the physicochemical characteristics and pharmacological effect of CARV on the nociception induced by Sarcoma 180 (S180) in experimental animals.

\section{Materials and methods}

\subsection{Chemicals}

Carvacrol (5-isopropyl-2-methylphenol, CARV, 98\% purity), $\beta$ cyclodextrin ( $\beta-C D)$, cremophor, sodium chloride, trypan blue were purchased from Sigma-Aldrich (St. Louis, Missouri, USA). Morphine and lactated ringer's solution were purchased from Cristália (São Paulo, São Paulo, Brazil).

\subsection{Preparation of inclusion complexes}

Inclusion complexes were prepared in two different procedures. A physical mixture (PM) was prepared with the addition of CARV (150 mg, based on its molecular weight) to an agate mortar containing powdered $\beta-C D$ under manual agitation. The $C A R V / \beta-C D$ molar ratio was maintained as described for inclusion complex preparation and the mechanical mixture was stored in airtight glass containers. Slurry complex (SC) was carried out by the addition of water to a beaker containing $1135 \mathrm{mg}$ of $\beta-\mathrm{CD}(3: 4, \mathrm{v} / \mathrm{w}, \mathrm{ml} /$ $\mathrm{mg})$. CARV (150 mg), which is equal to about a $1: 1 \mathrm{M}$ guest: host ratio, was added to the SC and stirred for $36 \mathrm{~h}$ by a magnetic stirring device operating at $400 \mathrm{rpm}$ (Quimis Q 261A21, Brazil). Thereafter, the mixture was transferred to an agate mortar, and dried in a desiccators [22].

\subsection{Thermal analysis}

Differential scanning calorimetry (DSC) curves were obtained in a DSC-50 cell (Shimadzu Corporation, Kyoto, Japan) using aluminum crucibles with about $2 \mathrm{mg}$ of samples, under dynamic nitrogen atmosphere $(50 \mathrm{ml} / \mathrm{min})$ and heating rate of $10^{\circ} \mathrm{C} / \mathrm{min}$ in the temperature range from 25 to $600{ }^{\circ} \mathrm{C}$. The DSC cell was calibrated with indium (m.p. $156.6^{\circ} \mathrm{C} ; \Delta$ Hfus. $=28.54 \mathrm{~J} / \mathrm{g}$ ) and zinc (m.p. $419.6^{\circ} \mathrm{C}$ ). Thermogravimetry/derivative thermogravimetry (TG/DTG) curves were obtained with a thermobalance (TGA 60, Shimadzu Corporation, Kyoto, Japan) in the temperature range $25-900{ }^{\circ} \mathrm{C}$, using platinum crucibles with $\sim 3 \mathrm{mg}$ of samples, under dynamic nitrogen atmosphere $(50 \mathrm{ml} / \mathrm{min})$ and heating rate of $10^{\circ} \mathrm{C} / \mathrm{min}$. Thermogravimetric system was calibrated using a $\mathrm{CaC}_{2-}$ $\mathrm{O}_{4} \cdot \mathrm{H}_{2} \mathrm{O}$ standard substance in conformity to the ASTM pattern.

\subsection{Scanning electron microscopy (SEM)}

The dried products were mounted on copper tape and visualized with a JEOL (Model JSM-7410-F SEM, JEOL USA, Inc. Peabody, MA, USA), at an accelerated voltage of $1 \mathrm{kV}$. Images were registered at $1000 \times$ and $2000 \times$ of magnification in order to study their surface.

\subsection{Animals}

For the realization of the experimental protocols, male Swiss mice were used (2-3 months of age; $28-32 \mathrm{~g}$ ), which were randomly housed in appropriate cages at $21 \pm 2{ }^{\circ} \mathrm{C}$ on a $12 \mathrm{~h}$ light/dark cycle with free access to food (Purina ${ }^{\circledR}$, Brazil) and water. Experimental protocols were approved by the Animal Care and Use Committee (CEPA/UFS 43/09) at the Federal University of Sergipe, and all handling procedures were in accordance with the International Association for the Study of Pain (IASP) guidelines for the use of animals in pain research [23]. All experiments involving the behavioral analysis were carried out by the same visual observer and in a double-blind manner.

\subsection{Tumor cell and implantation}

Sarcoma 180 (S180) tumor cells, obtained from the Laboratory of Experimental Oncology at the Federal University of Ceará (Brazil), were maintained in the peritoneal cavity of Swiss mice. Ten days after tumor implantation in the peritoneal cavity of the maintenance animals, Sarcoma 180 ascites tumor cells were checked for cell viability using trypan blue and a suspension of $10^{6}$ cells per $25 \mu \mathrm{L}$ of lactated ringer's solution were implanted subcutaneously in the hind paw of mice. This methodology was adapted from Kamioka et al. [24] and Lee et al. [25].

\subsection{Time-effect curve}

A time-effect curve was designed to evaluate the effect of the complexation in the pharmacological response of CARV on cancer pain. On the tenth day after the implantation of S180 in the hind paw of mice, they were treated with vehicle (saline), $C A R V / \beta-C D$ (50 mg/kg) or CARV (50 and $100 \mathrm{mg} / \mathrm{kg}$ ) orally (p.o.). The sensibility to mechanical stimulation was assessed 1, 3, 6, 9, 12, 24 and $27 \mathrm{~h}$ after treatment.

\subsection{Behavioral studies}

Indicative parameters of cancer pain as mechanical hyperalgesia, movement-evoked pain, spontaneous and palpation-induced nociception were evaluated after the treatment with vehicle or CARV $/ \beta-C D(12.5,25$ and $50 \mathrm{mg} / \mathrm{kg})$ from the 1 st to 15 th days following S180 administration. 


\subsection{Mechanical hyperalgesia}

Mice were evaluated as to the sensitivity towards mechanical stimulation generated by gradual increase in pressure of a handheld force transducer on the plantar surface of the hind paw (electronic anesthesiometer, model: EFF-301, Insight ${ }^{\circledR}$, Ribeirão Preto, São Paulo, Brazil) adapted with a polypropylene tip. In this test, there is the automatic recording of the intensity of the pressure able to evoke a hind paw flexion reflex that corresponds to the paw withdrawal followed by clear flinching movements, an indication of hyperalgesia. The intensity of stimulus was obtained by averaging five measurements performed with minimal intervals of $3 \mathrm{~min}$. The results are expressed by the $\Delta$ withdrawal threshold (in grams) calculated by subtracting the zero-time (basal) mean measurements from the time interval mean measurements [26].

\subsection{Spontaneous and palpation-induced nociception}

Animals were placed in scattered boxes and allowed to acclimate during $10 \mathrm{~min}$. Spontaneous pain was represented by flinching behaviors carried by the animals with S180 counted during a 10 -min period. After that, animals was submitted to non-noxious palpation of the paw with tumor during 2 min and the number of flinching behaviors was quantified for $2 \min [27]$.

\subsection{Movement-evoked pain}

We also evaluated the limb use through the observation of the mouse while walking in the same boxes scattered [28]. Limping and/or guarding behavior of the right (sarcoma-implanted) hind limb was rated on the following scale: $0=$ complete lack of use, 1 = partial non-use, 2 = limping and guarding, $3=$ limping, $4=$ normal walking.

\subsection{Measurement of forelimb grip strength}

The grip strength meter was carried before the treatment (p.o.) of tumor-free animals with vehicle or CARV/ $\beta-C D(12.5,25$ or
$50 \mathrm{mg} / \mathrm{kg}$ ) and 30, 60 and $120 \mathrm{~min}$ after treatment, using the commercial grip strength meter (EFF 305, Insight ${ }^{\circledR}$, Ribeirão Preto, São Paulo, Brazil), that digitally displays the maximum force applied (in grams) by mice. The mean of three consecutive trials was taken as an index of limb grip strength. To assess the limb grip strength measurement, the mice were held gently by the base of their tail over the top of the grid so that paws were able to grip the grid platform/T-bar [29].

\subsection{Statistical analysis}

The data obtained were evaluated using the Graph Pad Prism ( $\mathrm{v}$ 4.00) software (San Diego, CA, USA) by one- and two-way analysis of variance (ANOVA) followed by Tukey's test. Kruskal-Wallis followed by Dunn's test was applied forelimb use. In all cases, differences were considered significant if $p<0.05$.

\section{Results}

\subsection{Thermal analysis}

In the characterization of the complex, the DSC curve of CARV (Fig. 1) showed two endothermic events up to $120^{\circ} \mathrm{C}$ corresponding to its volatilization. The TG/DTG curves (Fig. 2) corroborate with this result, showing one step of weight loss of $100 \%$ up to $168^{\circ} \mathrm{C}$. DSC curve of $\beta-\mathrm{CD}$ showed four events of $27-600{ }^{\circ} \mathrm{C}$. The first event is related to the water releasing of $27-120^{\circ} \mathrm{C}$ $\left(\Delta_{\mathrm{m} 1}=11.8 \%\right)$. With the non-significant mass loss in the TG/DTG, the second event of $210-230^{\circ} \mathrm{C}$ was related the phase transition of $\beta$-CD. The other events are endothermically and exothermically assigned to fusion with thermal decomposition. TG/DTG curves showed thermal decomposition of $\beta-C D$ started above $270{ }^{\circ} \mathrm{C}$ and occurring with elemental carbon formation because of the sample carbonization. Between 360 and $900{ }^{\circ} \mathrm{C}$, the elemental carbon was slowly released.

Thus, the DSC curve of the PM indicated endothermic peaks: the first in the range of $62-86^{\circ} \mathrm{C}$, the second in the range of $86-130{ }^{\circ} \mathrm{C}$ (which corresponds to the release of water molecules as well as the

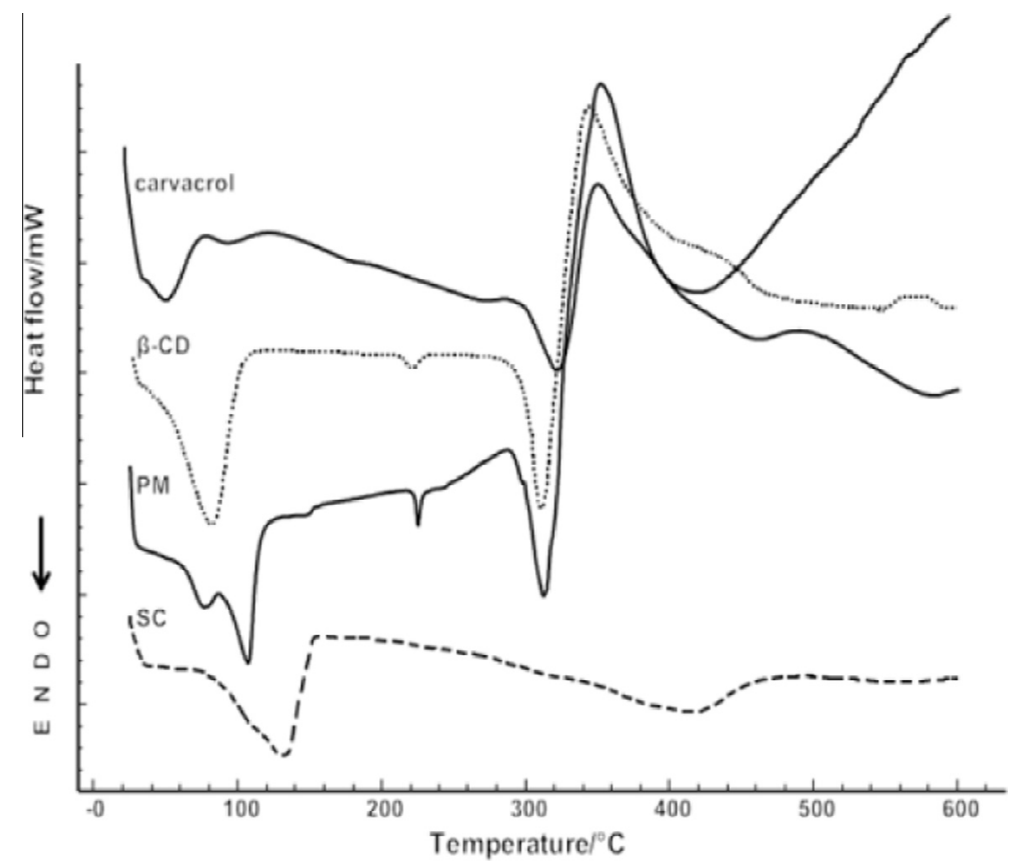

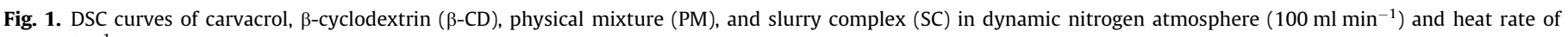
$10{ }^{\circ} \mathrm{C} \mathrm{min}^{-1}$. 


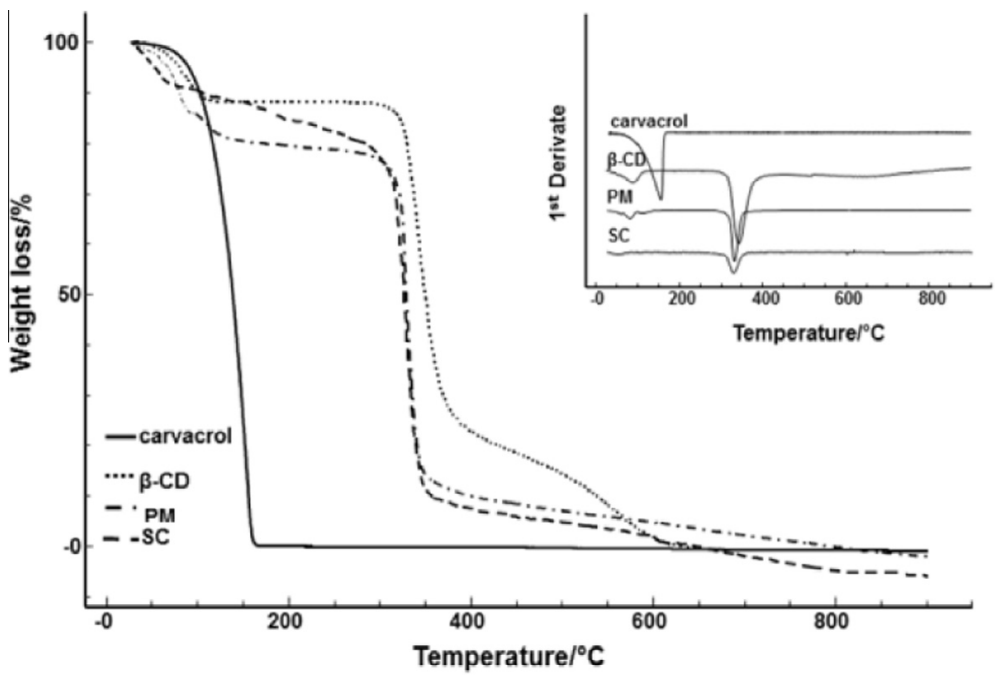

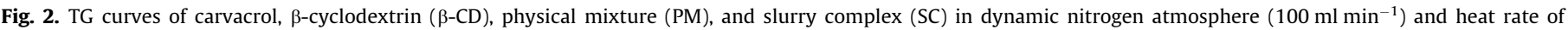
$10{ }^{\circ} \mathrm{C} \mathrm{min}^{-1}$.

Table 1

Mass losses for carvacrol, $\beta-C D, P M$ and SC (CARV/ $\beta-C D)$ complex.

\begin{tabular}{lllll}
\hline & \multicolumn{3}{l}{ Weight loss/\% } & \\
\cline { 2 - 5 } & 1 st step & 2ndstep & 3rdstep & 4th step \\
\hline Carvacrol & $100^{\mathrm{a}}$ & - & - & - \\
$\beta-C D$ & $11.8^{\mathrm{b}}$ & - & $72.88^{\mathrm{e}}$ & $10.76^{\mathrm{f}}$ \\
PM & $18.6^{\mathrm{c}}$ & $3.4^{\mathrm{d}}$ & $65.7^{\mathrm{e}}$ & $14.3^{\mathrm{f}}$ \\
SC & $11.2^{\mathrm{c}}$ & $8.7^{\mathrm{d}}$ & $70.9^{\mathrm{e}}$ & $15.2^{\mathrm{f}}$ \\
\hline
\end{tabular}

a Percentage of the carvacrol evaporates up to $168^{\circ} \mathrm{C}$.

b Percentage of water releasing up to $120^{\circ} \mathrm{C}$.

c Mass loss related to evaporation of the carvacrol and the water release up to $130^{\circ} \mathrm{C}$.

${ }^{d}$ Mass loss probably attributed to carvacrol release in the interval from 130 to $280{ }^{\circ} \mathrm{C}$.

e Thermal decomposition in the interval from 280 to $365^{\circ} \mathrm{C}$.

$\mathrm{f}$ Elemental carbon formation due to sample carbonization in the interval from 365 to $900{ }^{\circ} \mathrm{C}$

release of CARV, probably adsorbed in the surface), and an event similar to the phase transition of $\beta-C D$ of $220-230^{\circ} \mathrm{C}$. However, the DSC curve of the SC indicates only an endothermic event following decomposition.

The analysis of the TG/DTG curves evidences the complexation. The curves show $18.6 \%$ and $11.2 \%$ of mass loss up to $130{ }^{\circ} \mathrm{C}$ for PM and SC (Table 1), respectively. That can be attributed mainly to the water loss and to the release of surface oil for PM, but the weight loss of the SC is related to the release of a small amount of guest compound from the sample. Between 130 and $280^{\circ} \mathrm{C}$, the PM and SC lost $3.4 \%$ and $8.7 \%$, respectively. That means that through the slurry method, in this range, carvacrol strongly encapsulated is released, and at $\approx 280^{\circ} \mathrm{C}$, the decomposition of $\beta-C D$ molecules began to appear.

\subsection{Scanning electron microscopy (SEM)}

The Fig. 3 shows SEM images obtained for $\beta-C D$ (A1 and A2), PM (B1 and B2) and inclusion complex (C1 and C2) powders at different magnifications (1000 and $2000 \times$, respectively). The $\beta$-CD was composed by different sizes of rectangular-shaped crystals $(14.8 \pm 4.9 \mu \mathrm{m})$. Furthermore, they presented drastic changes in particle shapes and original morphologies of the inclusion complex products. The complexation between CARV and $\beta-C D$ appeared as agglomerates of size and smaller crystals $(7.5 \pm 2.6 \mu \mathrm{m})$. In contrast, the particle shapes and morphologies of the corresponding PMs were similar to those of $\beta-C D$. The particle sizes of the PMs $(80.2 \pm 28.3 \mu \mathrm{m})$ were much larger than those of the inclusion complex product and $\beta-\mathrm{CD}$ alone.

\subsection{Time-effect curve}

CARV in free form, when administered orally, showed a significant effect only at a dose of $100 \mathrm{mg} / \mathrm{kg}$, which was continued until $9 \mathrm{~h}$ after treatment. On the other hand, CARV $/ \beta-C D$ complex $(50 \mathrm{mg} / \mathrm{kg}$ ) was capable of promoting the same effect until $24 \mathrm{~h}$ after treatment. Thus, it was observed that the complexation increased the anti-hyperalgesic effect for 15 more hours (Fig. 4A).

\subsection{Mechanical hyperalgesia}

Subsequently, three increasing doses of the CARV $/ \beta-C D$ complex were tested (Fig. 4B). All doses of the complex (12.5 and $50 \mathrm{mg} / \mathrm{kg}$ : $p<0.01 ; 25 \mathrm{mg} / \mathrm{kg}: p<0.05)$ promoted a significant decrease in hyperalgesia induced by S180. After $24 \mathrm{~h}$, mice were reevaluated regarding the mechanical sensitivity and it was observed that they were still under the effect of the complex $(12.5 \mathrm{mg} / \mathrm{kg}: p<0.01 ; 25$ and $50 \mathrm{mg} / \mathrm{kg}$ : $p<0.05$ ) on the 11 th day. However, after $72 \mathrm{~h}$, mice were again sensitive towards mechanical stimulation, similarly to mice treated with vehicle alone (data not shown), requiring a new treatment for the effective control of pain. For this reason, a treatment interval for mice on alternate days was established.

This anti-hyperalgesic effect was also observed from the 12th to the 15th day, when mice were treated on alternate days with the complex at the doses of $12.5(p<0.001$ or 0.01$), 25(p<0.05)$, and $50 \mathrm{mg} / \mathrm{kg}(p<0.01$ or 0.05$)$. On the other hand, free CARV $(50 \mathrm{mg} / \mathrm{kg}$ ) orally administered was not able to promote statistically significant changes in hyperalgesic responses.

\subsection{Spontaneous and palpation-induced nociception}

All doses of the complex were able to reduce spontaneous and palpation-induced nociception in animals with S180 (Fig. 5A and B). Between the 10th and 15th days of the experiment, the animals were treated on alternate days with the complex at the doses of $12.5,25$ and $50 \mathrm{mg} / \mathrm{kg}$ of the CARV/ $\beta$-CD complex; they showed a statistically significant decrease in the number of spontaneous and post-palpation flinches $(p<0.001$ or 0.05$)$. Free CARV 

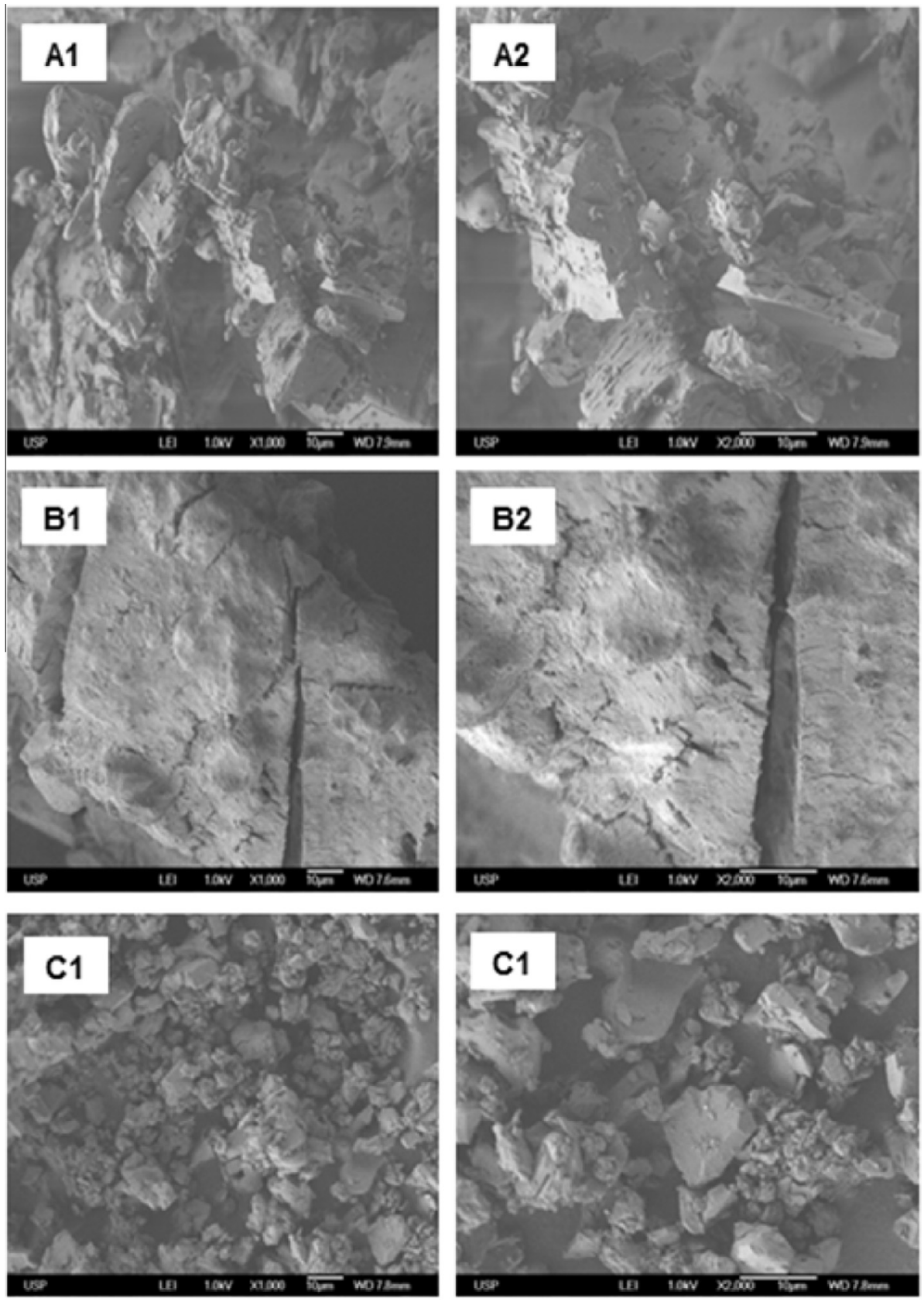

Fig. 3. SEM micrographs of cross-sections (1000 and $2000 \mu \mathrm{m})$ of (A) $\beta-C D$, (B) physical mixture (PM), and (C) slurry complex (SC).

(50 $\mathrm{mg} / \mathrm{kg}$ ) did not promote significant changes in nociceptive responses.

\subsection{Movement-evoked pain and measurement of forelimb grip strength}

CARV $/ \beta-C D$ complex did not promote significant changes in the limb use. Acute treatment of healthy animals with $C A R V / \beta-C D$ complex at the doses tested was not able to change the grip strength of animals at $30 \mathrm{~min}$ and $24 \mathrm{~h}$ after treatment, ruling out the hypothesis of a myorelaxing activity of this complex (data not shown).

\section{Discussion}

Cyclodextrins (CDs) are included in the group of pharmaceutical excipients, and represent one of the complexing agents most com- monly used by the pharmaceutical industry because they are inexpensive, friendly to humans and also capable of improving the biological, chemical and physical properties of bioactive molecules, especially those extracted from plants [30]. Now, we demonstrated that the complexation of carvacrol (CARV) with $\beta$-CD was able to improve the pharmacological response on cancer pain protocols.

DSC and TG/DTG curves demonstrated profiles similar to those already described in literature for CARV and $\beta-C D$ [31-34]. The difference in the DSC curves of the PM and the SC (or complex of CARV $/ \beta-C D$ ) clearly indicates a complex formation between the components. The curve of the PM was a superposition of the guest and host curves, which indicates a lower evidence of inclusion and significant interaction between the host and guest molecules. SEM indicated morphological differences in the products obtained, which is in agreement with the observations made by other authors [35-38]. The drastic change of the particle shapes and 

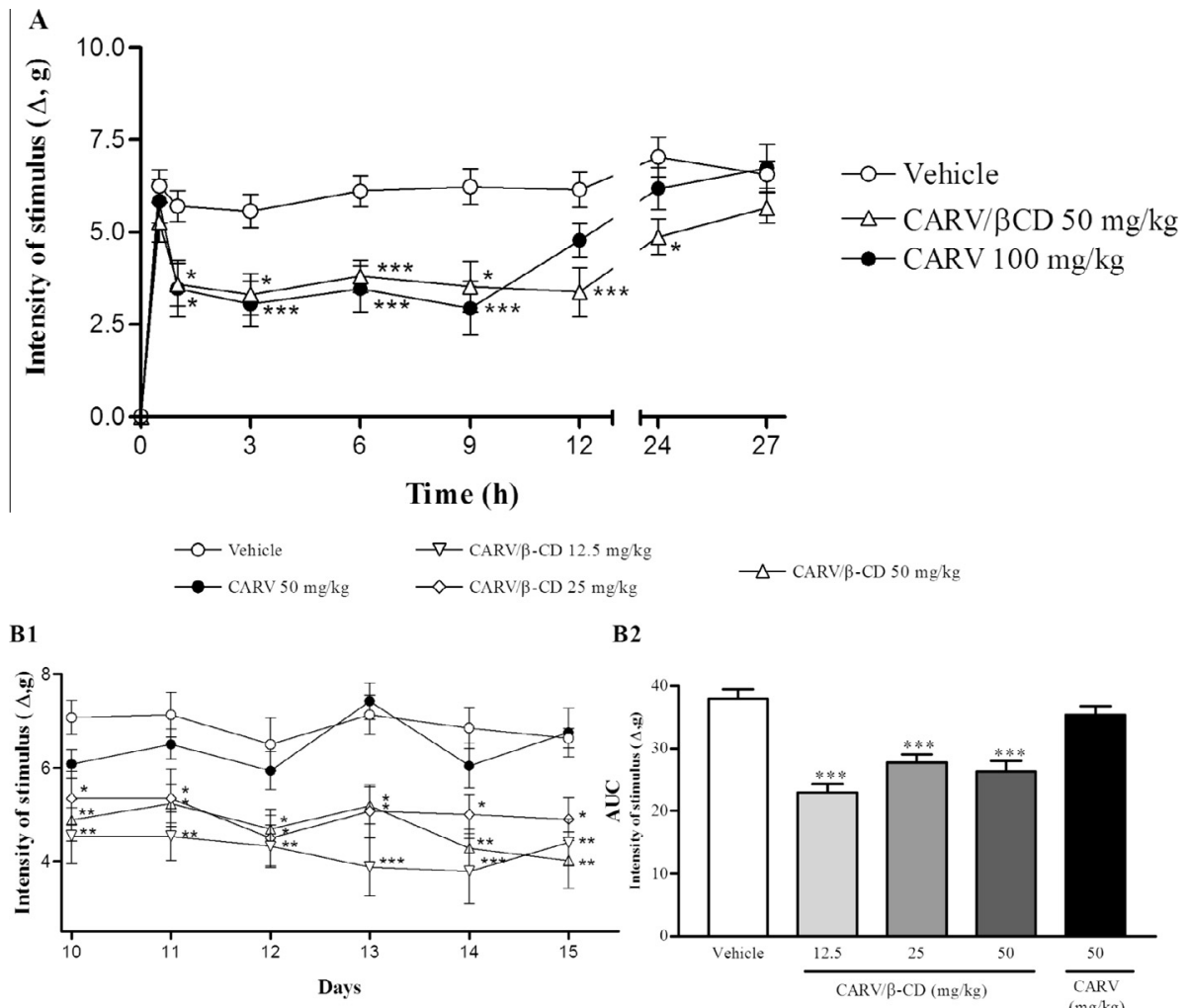

B2

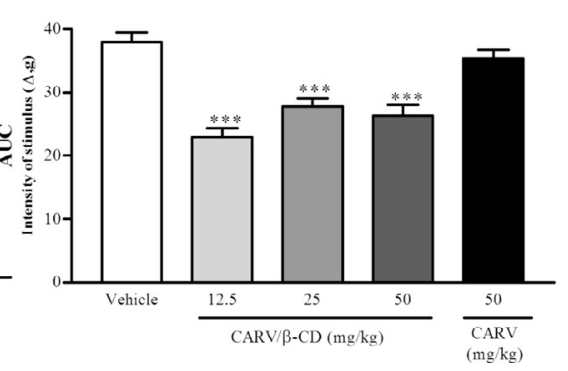

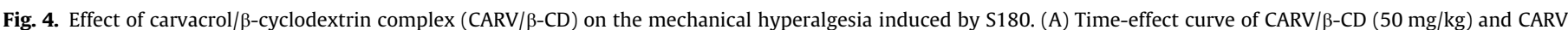

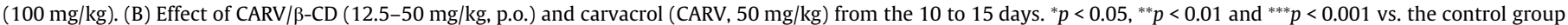
(vehicle) (ANOVA followed by Tukey's test).
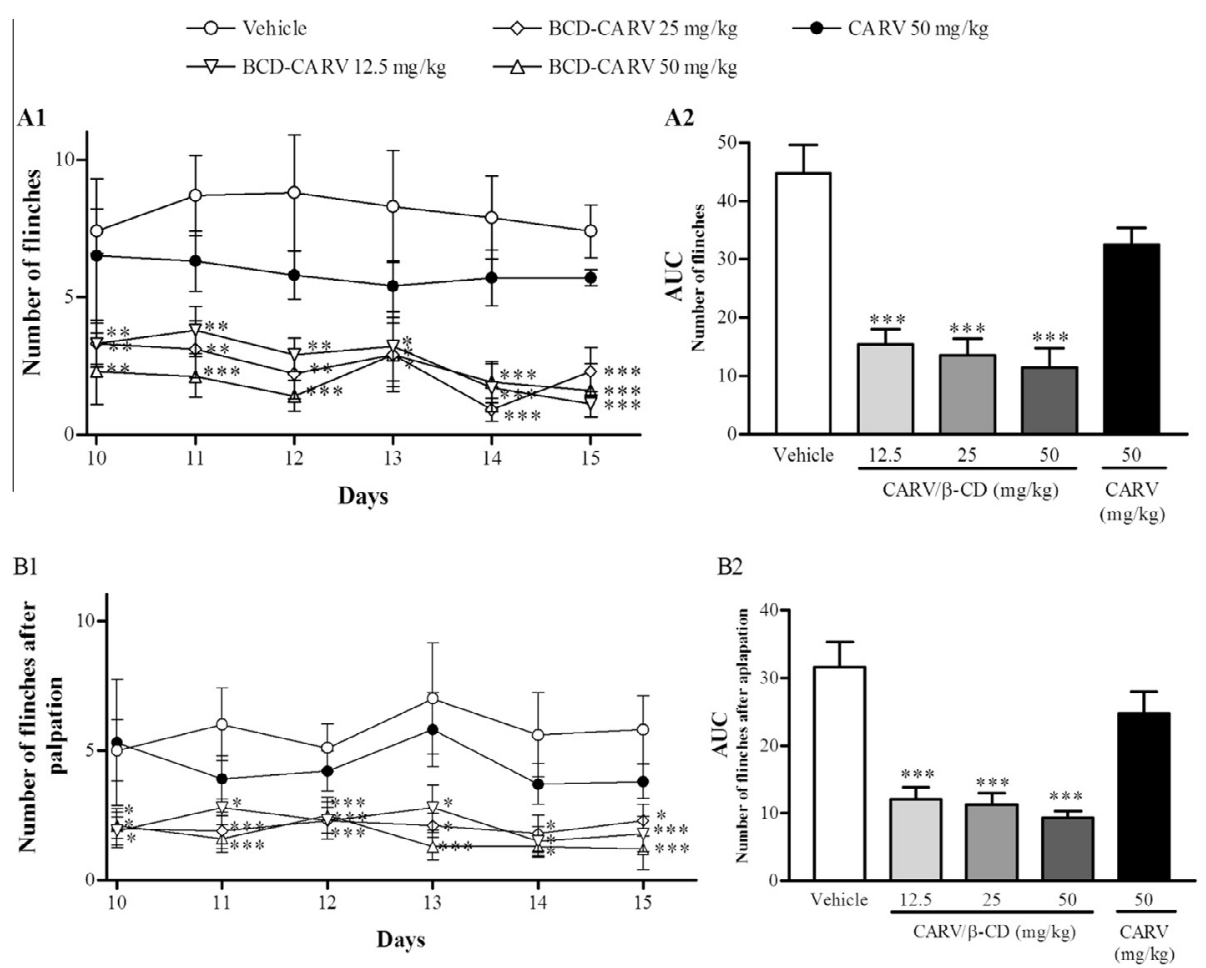

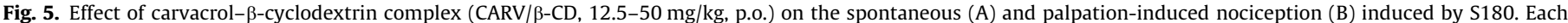

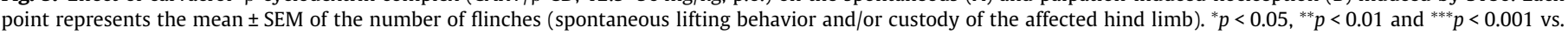
control group (ANOVA followed by Tukey's test). 
aspects in the co-evaporation sample were indicative of the presence of a new solid phase.

Bethanis et al. [39] and Mulinacci et al. [40] demonstrated through different methods that the CARV is found fully immersed inside the hydrophobic cavity of $\beta-C D$. This complex, when prepared with the co-precipitation method in aqueous solution, gives a complex monomer of $1 / 1$ stoichiometry, in which the isopropyl group of the CARV is located closer to the larger side of the hydrophobic cavity of $\beta-C D$. In aqueous medium, CDs are able to bind to organic molecules by non-covalent interactions and the complexation driving forces have been attributed to hydrophobic interactions, van der Waals-London dispersion forces, and hydrogen bonds [40].

Furthermore, Higueras et al. [41] recently developed a chitosan film in which the hydroxypropyl- $\beta$-cyclodextrins, a synthetic derivative of $\beta-C D$, was used to enhance: absorption of carvacrol by chitosan films, mechanical resistance and the properties of the barrier to the film water vapour. It also protected the preparation against thermal degradation. In this sense, chitosan films containing CDs are also employed as vehicle of active compounds in solid formulations, which can be applied topically for the treatment of skin disorders.

Carvacrol significantly reduced nociception induced by tumor cells and its complexation in $\beta-C D$ improved this pharmacological profile. Some studies have demonstrated that after oral administration, CARV is rapidly absorbed in the stomach and proximal small intestine, yielding a first peak of plasma concentration $(0.5 \mathrm{~h})$, presenting a second increase in plasmatic concentration between $2-8 \mathrm{~h}$, probably caused by re-uptake of CARV through enterohepatic recirculation [42-44].

Cyclodextrins are used in pharmaceutical applications for numerous purposes, including the improvement of the bioavailability of drugs, as well as the increase in the intensity or duration of therapeutic activity, especially for anti-inflammatory and antitumor drugs [17]. Furthermore, recent studies have shown that the encapsulation of plant bioactive compounds, such as essential oils and monoterpenes, promotes the increase in stability, solubility in aqueous environment, and also improves pharmacological activity $[19-21,30]$. In these cases, water-soluble CD complexes increase their diffusion to the mucosal surface of gastrointestinal tract leading to enhanced oral bioavailability [45].

This way, with the possible increase in CARV availability, there is a longer time to act on its action sites, as descending inhibitory pain pathway [13] through central neurotransmitters modulation, as dopamine and serotonin, and GABA and TRP receptors [10,46-50].

Encapsulation of CARV in $\beta-C D$ also can contribute to the inflammatory response control on peripheral tissues associated to the presence of tumor, through decrease in inflammatory mediators release, such as TNF- $\alpha$, IL- $1 \beta$, IL- 4 and PGE $_{2}$, endothelin, and suppression of the COX-2 and IL- $1 \beta$ expression $[11,14-16,51]$.

Is also interesting to note that all doses of the complex CARV $/ \beta$ $\mathrm{CD}$ tested were able to reduce nociception and hyperalgesia induced by Sarcoma 180, showing that the complexation of CARV in $\beta-C D$ was able to improve the pharmacological effect, even at lower doses. Thus, the reduction of the dose required for optimum therapeutic effect is one of the most important benefits of cyclodextrins in drug development. This result has been attributed to an increase in drug solubility when complexated in $C D$, resulting in the increase of drug potency and reducing the drug toxicity [52]

\section{Conclusions}

Thus, it was possible to demonstrate that the slurry complexation method showed a better inclusion profile of the carvacrol when compared to physical mixture. Besides, our results produced evidence that the encapsulation of carvacrol in $\beta$-cyclodextrin represents an interesting alternative to the development of new drugs for the cancer pain management, since it masks its organoleptic properties, increases stability, solubility and improves their ability to modulate the painful responses associated with cancer.

\section{Conflict of Interest}

The authors report no conflicts of interest. The authors alone are responsible for the content and writing of this paper.

\section{Transparency Document}

The Transparency document associated with this article can be found in the online version.

\section{Acknowledgements}

We thank Mr. Osvaldo Andrade Santos for the technical support. This work was supported by grants from the National Council of Technological and Scientific Development (CNPq/Brazil) and the Research Supporting Foundation of the State of Sergipe (FAPITECSE/Brazil).

\section{References}

11] J. Gaertner, C. Schiessl, Cancer pain management: what's new?, Curr Pain Headache Rep. 17 (2013) 328, http://dx.doi.org/10.1007/s11916-013-0328-9.

[2] G.E. Plante, T.B. VanItallie, Opioids for cancer pain: the challenge of optimizing treatment, Metabolism 59 (Suppl. 1) (2010) S47-S52, http://dx.doi.org/ 10.1016/j.metabol.2010.07.010.

[3] A.G. Guimarães, M.R. Serafini, L.J. Quintans-Júnior, Terpenes and derivatives as a new perspective for pain treatment: a patent review, Expert Opin. Ther. Pat. 24 (2014) 243-265, http://dx.doi.org/10.1517/13543776.2014.870154.

[4] R. de C. Da Silveira e Sá, L.N. Andrade, D.P. de Sousa, A review on antiinflammatory activity of monoterpenes, Mol. Basel Switz. 18 (2013) 12271254, http://dx.doi.org/10.3390/molecules18011227.

[5] D.P. De Sousa, Analgesic-like activity of essential oils constituents, Molecules 16 (2011) 2233-2252, http://dx.doi.org/10.3390/molecules16032233.

[6] A.G. Guimarães, J.S.S. Quintans, L.J. Quintans-Júnior, Monoterpenes with analgesic activity-a systematic review, Phytother. Res. PTR 27 (2013) 1-15, http://dx.doi.org/10.1002/ptr.4686.

[7] J.S.S. Quintans, A.R. Antoniolli, J.R.G.S. Almeida, V.J. Santana-Filho, L.J. Quintans-Júnior, Natural products evaluated in neuropathic pain models - a systematic review, Basic Clin. Pharmacol. Toxicol. 114 (2014) 442-450, http:// dx.doi.org/10.1111/bcpt.12178.

[8] K.H.C. Baser, Biological and pharmacological activities of carvacrol and carvacrol bearing essential oils, Curr. Pharm. Des. 14 (2008) 3106-3119.

[9] K.M. Arunasree, Anti-proliferative effects of carvacrol on a human metastatic breast cancer cell line, MDA-MB 231, Phytomedicine Int. J. Phytother.

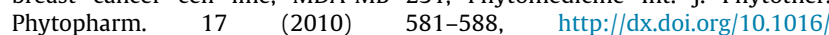
j.phymed.2009.12.008.

[10] F.H. Cavalcante Melo, E.R.V. Rios, N.F.M. Rocha, M.do C.de O. Citó, M.L. Fernandes, D.P. de Sousa, Antinociceptive activity of carvacrol (5-isopropyl-2methylphenol) in mice, J. Pharm. Pharmacol. 64 (2012) 1722-1729, http:// dx.doi.org/10.1111/j.2042-7158.2012.01552.x.

[11] A.G. Guimarães, M.A. Xavier, M.T. de Santana, E.A. Camargo, C.A. Santos, F.A. Brito, et al., Carvacrol attenuates mechanical hypernociception and inflammatory response, Naunyn. Schmiedebergs Arch. Pharmacol. 385 (2012) 253-263, http://dx.doi.org/10.1007/s00210-011-0715-x.

[12] A.G. Guimarães, G.F. Oliveira, M.S. Melo, S.C.H. Cavalcanti, A.R. Antoniolli, L.R. Bonjardim, et al., Bioassay-guided evaluation of antioxidant and antinociceptive activities of carvacrol, Basic Clin. Pharmacol. Toxicol. 107 (2010) 949-957, http://dx.doi.org/10.1111/j.1742-7843.2010.00609.x.

[13] A.G. Guimarães, L. Scotti, M.T. Scotti, F.J.B. Mendonça Júnior, N.S.R. Melo, R.S. Alves, et al., Evidence for the involvement of descending pain-inhibitory mechanisms in the attenuation of cancer pain by carvacrol aided through a docking study, Life Sci. (2014), http://dx.doi.org/10.1016/j.lfs.2014.08.020.

[14] M. Hotta, R. Nakata, M. Katsukawa, K. Hori, S. Takahashi, H. Inoue, Carvacrol, a component of thyme oil, activates PPARalpha and gamma and suppresses COX-2 expression, J. Lipid Res. 51 (2010) 132-139, http://dx.doi.org/10.1194/ jlr.M900255-JLR200. 
[15] S. Jalali, M.H. Boskabady, A. Haeri-Rohani1, A. Eidi, The effect of carvacrol on serum cytokines and endothelin levels of ovalbumin sensitized Guinea-pigs, Iran. J. Basic Med. Sci. 16 (2013) 607-611.

[16] M. da S. Lima, L.J. Quintans-Júnior, W.A. de Santana, C. Martins Kaneto, M.B. Pereira Soares, C.F. Villarreal, Anti-inflammatory effects of carvacrol: evidence for a key role of interleukin-10, Eur. J. Pharmacol. 699 (2013) 112-117.

[17] S.V. Kurkov, T. Loftsson, Cyclodextrins, Int. J. Pharm. 453 (2013) 167-180, http://dx.doi.org/10.1016/j.ijpharm.2012.06.055.

[18] H.M.C. Marques, A review on cyclodextrin encapsulation of essential oils and volatiles, Flavour Fragr. J. 25 (2010) 313-326, http://dx.doi.org/10.1002/ ffj.2019.

[19] J. de S.S. Quintans, P.P. Menezes, M.R.V. Santos, L.R. Bonjardim, J.R.G.S. Almeida, D.P. Gelain, Improvement of p-cymene antinociceptive and antiinflammatory effects by inclusion in $\beta$-cyclodextrin, Phytomedicine Int. J. Phytother. Phytopharm. 20 (2013) 436-440, http://dx.doi.org/10.1016/ j.phymed.2012.12.009.

[20] L.J. Quintans-Júnior, R.S.S. Barreto, P.P. Menezes, J.R.G.S. Almeida, A.F.S.C. Viana, R.C.M. Oliveira, et al., $\beta$-Cyclodextrin-complexed (-)-linalool produces antinociceptive effect superior to that of (-)-linalool in experimental pain protocols, Basic Clin. Pharmacol. Toxicol. 113 (2013) 167-172, http:// dx.doi.org/10.1111/bcpt.12087.

[21] P.S. Siqueira-Lima, A.A.S. Araújo, A.M. Lucchese, J.S.S. Quintans, P.P. Menezes, P.A. Barreto, et al., $\beta$-Cyclodextrin complex containing Lippia grata leaf essential oil reduces orofacial nociception in mice - evidence of possible involvement of descending inhibitory pain modulation pathway, Basic Clin. Pharmacol. Toxicol. (2014), http://dx.doi.org/10.1111/bcpt.12145.

[22] P.P. Menezes, M.R. Serafini, B.V. Santana, R.S. Nunes, L.J. Quintans-Júnior, G.F. Silva, et al., Solid-state $\beta$-cyclodextrin complexes containing geraniol, Thermochim. Acta 548 (2012) 45-50, http://dx.doi.org/10.1016/ j.tca.2012.08.023.

[23] M. Zimmermann, Ethical guidelines for investigations of experimental pain in conscious animals, Pain 16 (1983) 109-110.

[24] H. Kamioka, S. Osaka, K. Suzuki, J. Ryu, Suppressive effects of bisphosphonate on bone resorption induced by murine sarcoma, Nihon Univ. J. Med. 41 (1999) $121-133$.

[25] H.-J. Lee, J.-H. Lee, E.-O. Lee, H.-J. Lee, K.-H. Kim, S.-H. Kim, et al., Substance P and beta-endorphin mediate electro-acupuncture induced analgesia in mouse cancer pain model, J. Exp. Clin. Cancer Res. CR 28 (2009) 102, http://dx.doi.org/ 10.1186/1756-9966-28-102.

[26] T.M. Cunha, W.A. Verri, J.S. Silva, S. Poole, F.Q Cunha, S.H. Ferreira, A cascade of cytokines mediates mechanical inflammatory hypernociception in mice, Proc. Natl. Acad. Sci. U.S.A. 102 (2005) 1755-1760, http://dx.doi.org/10.1073/ pnas.0409225102.

[27] M.A.C. Sabino, N.M. Luger, D.B. Mach, S.D. Rogers, M.J. Schwei, P.W. Mantyh, Different tumors in bone each give rise to a distinct pattern of skeletal destruction, bone cancer-related pain behaviors and neurochemical changes in the central nervous system, Int. J. Cancer 104 (2003) 550-558, http:// dx.doi.org/10.1002/ijc.10999.

[28] N.M. Luger, P. Honore, M.A. Sabino, M.J. Schwei, S.D. Rogers, D.B. Mach, et al., Osteoprotegerin diminishes advanced bone cancer pain, Cancer Res. 61 (2001) 4038-4047.

[29] H. van Riezen, L. Boersma, A new method for quantitative grip strength evaluation, Eur. J. Pharmacol. 6 (1969) 353-356.

[30] E. Pinho, M. Grootveld, G. Soares, M. Henriques, Cyclodextrins as encapsulation agents for plant bioactive compounds, Carbohydr. Polym. 101 (2014) 121-135, http://dx.doi.org/10.1016/j.carbpol.2013.08.078.

[31] M. Ramos, A. Jiménez, M. Peltzer, M.C. Garrigós, Characterization and antimicrobial activity studies of polypropylene films with carvacrol and thymol for active packaging, J. Food Eng. 109 (2012) 513-519, http:// dx.doi.org/10.1016/j.jfoodeng.2011.10.031.

[32] C. Rodríguez-Tenreiro, C. Alvarez-Lorenzo Á Concheiro JJ. Torres-Labandeira, Characterization of cyclodextrincarbopol interactions by DSC and FTIR, J. Therm. Anal. Calorim. 77 (2004) 403-411, http://dx.doi.org/10.1023/ B:JTAN.0000038981.30494.f4.

[33] M.R. Serafini, P.P. Menezes, L.P. Costa, C.M. Lima, L.J. Quintans-Júnior, J.C Cardoso, et al., Interaction of p-cymene with $\beta$-cyclodextrin, J. Therm. Anal. Calorim. 109 (2012) 951-955, http://dx.doi.org/10.1007/s10973011-1736-x.

[34] P. Xu, L.X. Song, H.M. Wang, Study on thermal decomposition behavior of survived $\beta$-cyclodextrin in its inclusion complex of clove oil by nonisothermal thermogravimetry and gas chromatography coupled to time-of-flight mass spectrometry analyses, Thermochim. Acta 469 (2008) 36-42, http://dx.doi.org 10.1016/j.tca.2007.12.009.

[35] C. dos Santos, M.P. Buera, M.F. Mazzobre, Influence of ligand structure and water interactions on the physical properties of $\beta$-cyclodextrins complexes, Food Chem. 132 (2012) 2030-2036, http://dx.doi.org/10.1016/ j.foodchem.2011.12.044.

[36] N.G. Hădărugă, Ficaria verna Huds. extracts and their $\beta$-cyclodextrin supramolecular systems, Chem. Cent. J. 6 (2012) 16, http://dx.doi.org/ 10.1186/1752-153X-6-16.

[37] P.P. Menezes, M.R. Serafini, L.J. Quintans-Júnior, G.F. Silva, J.F. Oliveira, F.M.S Carvalho, et al., Inclusion complex of (-)-linalool and $\beta$-cyclodextrin, J. Therm. Anal. Calorim. 115 (2014) 2429-2437, http://dx.doi.org/10.1007/s10973-0133367-x.

[38] S. Songkro, N. Hayook, J. Jaisawang, D. Maneenuan, T. Chuchome, N Kaewnopparat, Investigation of inclusion complexes of citronella oil, citronellal and citronellol with $\beta$-cyclodextrin for mosquito repellent, J. Incl. Phenom. Macrocycl. Chem. 72 (2012) 339-355, http://dx.doi.org/10.1007/ s10847-011-9985-7.

[39] K. Bethanis, P. Tzamalis, F. Tsorteki, A Kokkinou, E. Christoforides, D. Mentzafos, Structural study of the inclusion compounds of thymol, carvacrol and eugenol in $\beta$-cyclodextrin by X-ray crystallography, J. Incl. Phenom. Macrocycl. Chem. 77 (2013) 163-173, http://dx.doi.org/10.1007/s10847-0120230-9.

[40] N. Mulinacci, F. Melani, F.F. Vincieri, G. Mazzi, A. Romani, 1H-NMR NOE and molecular modelling to characterize thymol and carvacrol $\beta$-cyclodextrin complexes, Int. J. Pharm. 128 (1996) 81-88, http://dx.doi.org/10.1016/03785173(95)04224-5.

[41] L. Higueras, G. López-Carballo, J.P. Cerisuelo, R. Gavara, P. Hernández-Muñoz, Preparation and characterization of chitosan/HP- $\beta$-cyclodextrins composites with high sorption capacity for carvacrol, Carbohydr. Polym. 97 (2013) 262268, http://dx.doi.org/10.1016/j.carbpol.2013.04.007.

[42] K.H.C. Baser, G. Buchbauer, Handbook of Essential Oils: Science, Technology, and Applications, CRC Press, 2009.

[43] M. Beck, M. Bruchlen, V. Elste, P. Mair, R. Rümbeli, Posters: Studying Absorption, Distribution, Metabolism, and Excretion of a Complex Extract, in: Deutsche Forschungsgemeinschaft (Ed.), Risk Assess. Phytochem. Food, Wiley-VCH Verlag GmbH \& Co. KGaA, 2010, pp. 361-466. http:// onlinelibrary.wiley.com/doi/10.1002/9783527634705.ch4/summary (accessed December 25, 2013).

[44] J. Michiels, J. Missotten, N. Dierick, D. Fremaut, P. Maene, S. De Smet, In vitro degradation and in vivo passage kinetics of carvacrol, thymol, eugenol and trans-cinnamaldehyde along the gastrointestinal tract of piglets, J. Sci. Food Agric. 88 (2008) 2371-2381, http://dx.doi.org/10.1002/jsfa.3358.

[45] T. Loftsson, P. Jarho, M. Másson, T. Järvinen, Cyclodextrins in drug delivery, Expert Opin. Drug Deliv. 2 (2005) 335-351, http://dx.doi.org/10.1517/ 17425247.2.1.335.

[46] H.C. Joca, Y. Cruz-Mendes, K. Oliveira-Abreu, R.P.M. Maia-Joca, R. Barbosa, T.L Lemos, et al., Carvacrol decreases neuronal excitability by inhibition of voltage-gated sodium channels, J. Nat. Prod. 75 (2012) 1511-1517, http:// dx.doi.org/10.1021/np300050g.

[47] F.H.C. Melo, B.A. Moura, D.P. de Sousa, S.M.M. de Vasconcelos, D.S. Macedo, M.M. de F. Fonteles, Antidepressant-like effect of carvacrol (5-Isopropyl-2methylphenol) in mice: involvement of dopaminergic system, Fundam. Clin. Pharmacol. $25 \quad$ (2011) 362-367, http://dx.doi.org/10.1111/j.14728206.2010.00850.x.

[48] F.H.C. Melo, E.T. Venâncio, D.P. de Sousa, M.M. de França Fonteles, S.M.M. de Vasconcelos, G.S.B. Viana, et al., Anxiolytic-like effect of carvacrol (5isopropyl-2-methylphenol) in mice: involvement with GABAergic transmission, Fundam. Clin. Pharmacol. 24 (2010) 437-443, http:// dx.doi.org/10.1111/j.1472-8206.2009.00788.x.

[49] M. Parnas, M. Peters, D. Dadon, S. Lev, I. Vertkin, I. Slutsky, et al., Carvacrol is a novel inhibitor of Drosophila TRPL and mammalian TRPM7 channels, Cel Calcium 45 (2009) 300-309, http://dx.doi.org/10.1016/j.ceca.2008.11.009.

[50] A.K. Vogt-Eisele, K. Weber, M.A. Sherkheli, G. Vielhaber, J. Panten, G. Gisselmann, et al., Monoterpenoid agonists of TRPV3, Br. J. Pharmacol. 151 (2007) 530-540, http://dx.doi.org/10.1038/sj.bjp.0707245.

[51] H. Wagner, M. Wierer, R. Bauer, In vitro inhibition of prostaglandin biosynthesis by essential oils and phenolic compounds, Planta Med. (1986) 184-187.

[52] G. Tiwari, R. Tiwari, A. Rai, Cyclodextrins in delivery systems: applications, J. Pharm. Bioallied Sci. 2 (2010) 72, http://dx.doi.org/10.4103/0975-7406.67003. 